\title{
Propriedades tensiométricas comparadas entre fragmentos do centro tendíneo do diafragma, pericárdio fibroso e peritônio parietal de bovinos não conservados e conservados em glicerina
}

\author{
Gregório Corrêa \\ GUIMARÃES ${ }^{1}$ \\ Márcia Rita Fernandes \\ $\mathrm{MACHADO}^{2}$ \\ Antônio Carlos SHIMANO ${ }^{3}$ \\ César Augusto Sangaleti \\ TERÇARIOL ${ }^{1}$ \\ José Batista VOLPON ${ }^{3}$ \\ Carlos Roberto DALECK ${ }^{2}$
}

\section{Correspondência para:}

Gregório Corrêa Guimarães, Departamento de Morfologia e Fisiologia Animal da FCAV/UNESP. Via de Acesso Professor Paulo Donato Castellane, S/n. 14884-900. Jaboticabal - SP. E-mail: gregorio_g@yahoo.com

\author{
1 - Curso de Medicina Veterinária do Centro Universitário Barão de Mauá, Ribeirão \\ Preto-SP \\ 2 - Faculdade de Ciências Agrárias e Veterinárias da Universidade Estadual Paulista \\ Júlio de Mesquita Filho, Jaboticabal-SP \\ 3 - Departamento de Biomecânica, Medicina e Reabilitação do Aparelho \\ Locomotor e Laboratório de Bioengenharia da Faculdade de Medicina de Ribeirão \\ Preto da Universidade de São Paulo, Ribeirão Preto-SP
}

\section{Resumo}

Objetivou-se descrever o comportamento do centro tendíneo do diafragma, pericárdio fibroso e peritônio parietal de bovinos não conservados e conservados em glicerina a 98\% durante 30, 60 e 90 dias submetidos a ensaios mecânicos de tração. Utilizou-se para tanto dez bovinos com idade entre 30 meses e 36 meses, mestiços, machos e fêmeas, coletando-se de cada animal fragmentos das membranas referidas. O centro tendíneo do diafragma e o peritônio parietal não sofreram alteração significante $(p>0,05)$ para os valores de tensão quando comparados os testes de resistência à tração do material não conservado com aqueles conservados em glicerina. Entretanto, todos os tecidos avaliados exibiram aumento significante $(\mathrm{p} £, 0,05)$ para os valores de alongamento quando conservados em glicerina $98 \%$ por até 90 dias. Verificou-se que o pericárdio fibroso é a membrana que suporta as maiores tensões, ou seja, maior força de tração por área de secção. Assim, concluiu-se que a glicerina é eficaz para conservação de membranas biológicas, além de alterar suas propriedades mecânicas.
Palavras-chave: Bovinos.

Centro tendíneo.

Pericárdio.

Peritônio.

Ensaios mecânicos.

\section{Introdução}

As membranas biológicas podem ser obtidas a partir de diferentes espécies animais e têm sido utilizadas como material de implante para reparação de órgãos e tecidos. ${ }^{1}$ Seu estudo no Brasil teve início a partir da década de 1960, cujo trabalho pioneiro foi realizado por Pigossi ${ }^{2}$ ao utilizar dura-máter canina conservada em glicerina. $\mathrm{O}$ emprego destes tecidos deve-se, principalmente, à facilidade de obtenção, baixo custo, preparo simples, esterilização viável, facilidade na estocagem, além de pouca ou nenhuma reação tecidual. $^{3}$

O objetivo principal é fornecer um arcabouço para a orientação e para o desenvolvimento de novos tecidos, mediante processo de reparação que restabeleça a estrutura e a função do órgão afetado. ${ }^{1}$

Desde os primeiros estudos realizados sobre a viabilidade do uso de membranas biológicas como agentes reparadores de órgãos e tecidos, poucos foram os trabalhos que enfocaram ensaios biomecânicos dessas membranas no intuito de conhecer sua resistência à tração, bem como a capacidade de distensão de suas fibras. ${ }^{1}$

Os estudos biomecânicos têm por objetivo determinar as propriedades mecânicas de um material e dependendo de suas características físicas, pode-se submetêlo aos ensaios de tração, torção, compressão e flexão ${ }^{1}$. A mensuração da resistência dos materiais implantados avalia a capacidade desses implantes em suportar tensão caso 
venham a ser utilizados clinicamente. ${ }^{4}$

Os testes de resistência consistem na aplicação de ensaios uniaxiais como pressão de explosão, força de ruptura à tração e tensão de ruptura. Estes modelos analisam um ou dois atributos no momento crítico de ruptura e, apesar de serem muito empregados, os resultados obtidos representam apenas parcialmente o comportamento do tecido biológico sob imposição de uma força externa e variável com o tempo. ${ }^{5}$

Assim, com o presente trabalho objetivou-se descrever o comportamento do centro tendíneo do diafragma, pericárdio fibroso e peritônio parietal de bovinos não conservados e conservados em glicerina, submetidos a ensaios mecânicos de tração.

\section{Material e Método}

Este projeto não envolveu qualquer manipulação com os animais in vivo, quer seja estresse, dor, administração de fármacos, inclusive uso de drogas anestésicas e, principalmente, não realizou a eutanásia dos animais.

Para tanto se utilizou material de dez bovinos com idade entre 30 meses e 36 meses, mestiços, machos e fêmeas, obtendose de cada um três membranas, quais sejam, centro tendíneo do diafragma, pericárdio fibroso e peritônio parietal, colhidos após abate dos animais, no Frigorífico Barra Mansa Comércio de Carnes e Derivados Ltda., Sertãozinho, São Paulo.

A colheita foi realizada retirando-se fragmentos de cada membrana, sempre de uma mesma região anatômica na carcaça de cada animal e procurando manter a homogeneidade entre as amostras. Estas foram devidamente lavadas em água corrente para retirada de resíduos e acondicionadas em recipientes plásticos contendo solução fisiológica de $\mathrm{NaCl}$ 0,9\%.

$O$ ensaio mecânico de tração foi realizado no Laboratório de Bioengenharia da Faculdade de Medicina de Ribeirão Preto, da Universidade de São Paulo. No laboratório o material foi novamente lavado e imerso em solução fisiológica de $\mathrm{NaCl}$ $0,9 \%$, retirando-se toda a gordura e aderências. Em seguida foi colocado sob guilhotina, obtendo-se quatro corpos de prova em série. A guilhotina foi desenvolvida com objetivo de se obter amostras padronizadas nas dimensões de $20 \mathrm{~mm}$ de largura por $200 \mathrm{~mm}$ de comprimento. Após o corte do material, cada corpo de prova foi devidamente enumerado com o número dos animais para sua correta identificação e comparação.

Assim, dos quatro corpos de prova obtidos a partir de cada amostra coletada, a primeira era testada em seguida ao corte, ou seja, avaliava-se o material não conservado; as três amostras restantes foram marcadas com o número do respectivo animal e colocadas em recipientes distintos contendo glicerina para avaliação aos 30, 60 e 90 dias pós-colheita. Desse modo, a cada ensaio mecânico havia amostras de todos os animais avaliados, com total de dez corpos de prova a cada teste, realizando-se 40 avaliações para o centro tendíneo do diafragma $(0,30,60$ e 90 dias), pericárdio fibroso $(0,30,60$ e 90 dias) e peritônio parietal (0, 30, 60 e 90 dias), e ao final, um total de 120 testes.

Os recipientes onde foram armazenadas as membranas biológicas continham glicerina a $98 \%$ numa proporção de 20:1 (glicerina/membrana), mantidos em temperatura ambiente e identificados com o nome do material, a data de colheita e o meio de preservação.

Anteriormente à realização dos ensaios mecânicos, os corpos de prova glicerinados foram reidratados em água por pelo menos 20 minutos, não excedendo os 90 minutos, para representar as condições que as membranas são submetidas nos períodos pré e trans-operatório.

Os testes foram realizados em máquina universal de ensaio EMIC $^{\circledR}$ (modelo DL 10000). A máquina possui interface direta a um microcomputador com o software Tesc ${ }^{\mathbb{R}}$, capaz de gerar gráficos da força versus deformação (alongamento), para cada ensaio.

Para fixação dos corpos de prova na 
máquina foi utilizado acessório que contém ranhuras em sua superfície, as quais auxiliam nesse processo mediante compressão realizada pelo ajuste de um parafuso, evitando o deslizamento do material durante o ensaio.

No momento dos ensaios, os corpos de prova foram acoplados à máquina e, conforme metodologia estabelecida pelo Laboratório de Bioengenharia, foi aplicada pré-carga de 200 gramas $(2 \mathrm{~N})$ durante 30 segundos, com intuito de promover acomodação do sistema, evitando-se possíveis folgas no conjunto máquina, acessório e modelo ensaiado. Todo o material foi mensurado com paquímetro Mitutoyo ${ }^{\circledR}$, anteriormente à realização dos testes, aferindo-se suas medidas de largura e espessura, parâmetros estes que interferem diretamente na área de secção das amostras. Todos os corpos de prova tiveram seu comprimento padronizado em $50 \mathrm{~mm}$ entre os acessórios de fixação da máquina de ensaio.

Após a pré-carga o ensaio prosseguiu, em média, por 5 minutos, com velocidade pré-estabelecida em $10 \mathrm{~mm} / \mathrm{min}$. A carga aplicada foi registrada pelo software em intervalos regulares de alongamento até o momento da ruptura das membranas (Figura 1).

Os dados foram agrupados e descritos pela estatística descritiva por meio de valores médios, erro-padrão e desviopadrão. Os grupos de centro tendíneo do diafragma, pericárdio fibroso e peritônio
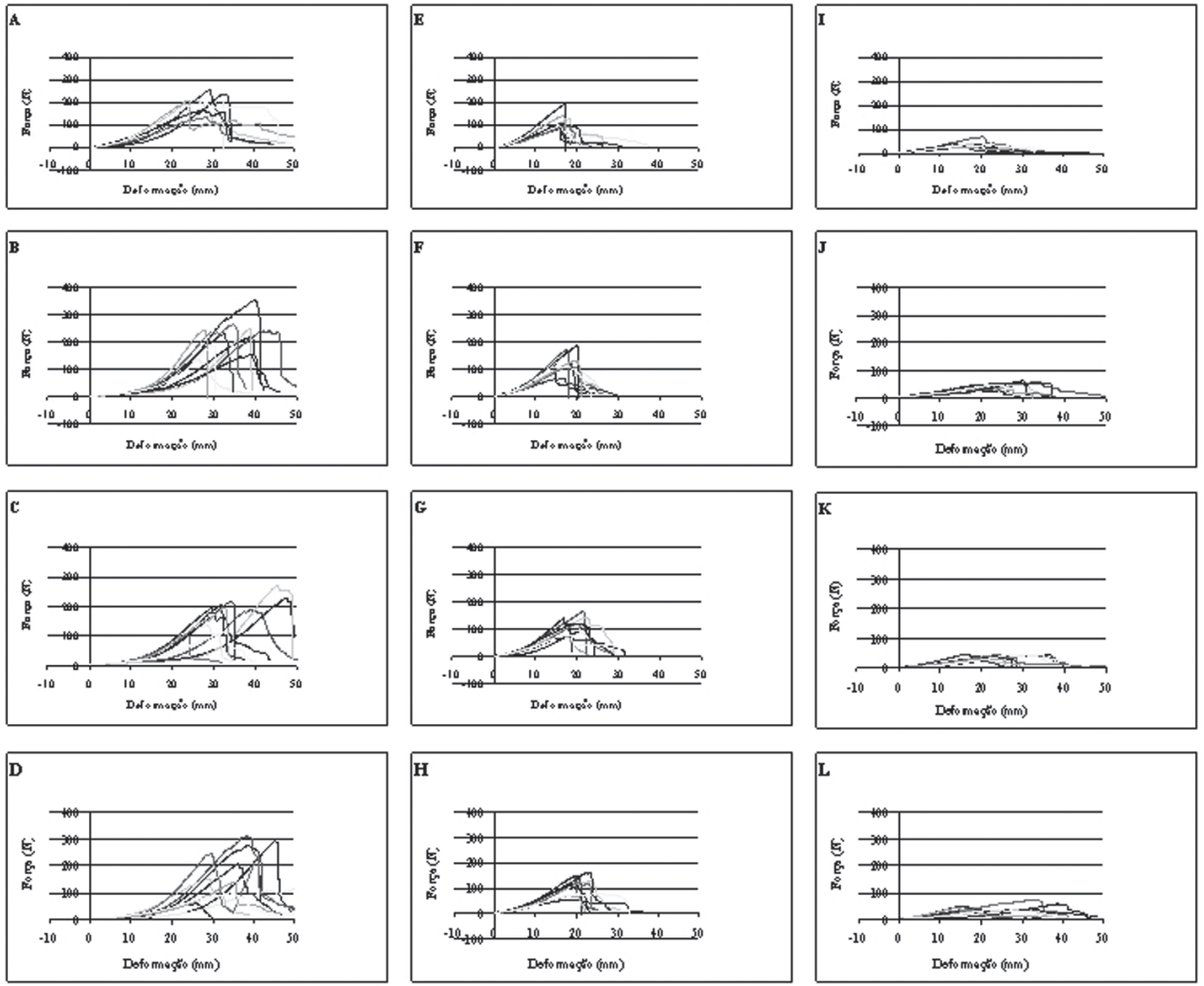

Figura 1 - Gráficos força versus deformação. A-D. Ensaios com amostras de centro tendíneo do diafragma bovino: material não conservado (A), 30 dias em glicerina (B), 60 dias em glicerina (C) e 90 dias em glicerina (D); $\mathrm{E}-\mathrm{H}$. Ensaios com amostras de pericárdio fibroso bovino: material não conservado (E), 30 dias em glicerina (F), 60 dias em glicerina (G) e 90 dias em glicerina (H); I-L. Ensaios com amostras de peritônio parietal bovino: material não conservado (I), 30 dias em glicerina (J), 60 dias em glicerina (K) e 90 dias em glicerina $(\mathrm{L})$ 
parietal foram comparados pelo teste $t$ Student não-pareado, com nível de significância igual a $5 \%(\mathrm{p} \leq 0,05)$ adotado em todas as comparações. ${ }^{6}$

A tensão de cada corpo de prova é, por definição, a razão força máxima aplicada / área de secção. O valor médio da tensão se refere à média aritmética simples das tensões de cada corpo de prova enumerados de 0 a 10, o que não equivale algebricamente à razão força máxima média / área média apresentado nas tabelas 1 a 3 . O mesmo se aplica ao desvio-padrão da tensão.

Este projeto foi aprovado pelo Comitê de Ética em Pesquisa da Faculdade de Ciências Agrárias e Veterinárias da UNESP campus de Jaboticabal de acordo com as resoluções específicas para experimentos com animais.

\section{Resultados}

A ruptura dos corpos de prova ocorreu quase que na sua totalidade em região central, embora em alguns exemplares de centro tendíneo do diafragma, ela ocorreu junto à sua intersecção com a parte mediastinal da pleura parietal, deslocando o ponto de ruptura para as extremidades do segmento avaliado.

Analisando-se o gráfico referente à força versus alongamento, foram obtidas e analisadas as seguintes propriedades mecânicas: força máxima de tração, tensão máxima e alongamento, que foram agrupadas e expressas nas tabelas 1 a 5 .

Das observações referentes aos testes físicos realizados com o centro tendíneo do diafragma (Tabela 1), constatou-se que tanto nas amostras não conservadas $(0,66 \mathrm{kgf} /$ $\mathrm{mm}^{2}$ ) quanto naquelas conservadas em glicerina a $98 \%$, durante 30 dias $(0,61 \mathrm{kgf} /$ $\left.\mathrm{mm}^{2}\right), 60$ dias $\left(0,57 \mathrm{kgf} / \mathrm{mm}^{2}\right)$ e 90 dias $(0,60$ $\left.\mathrm{kgf} / \mathrm{mm}^{2}\right)$, não houve alteração significante na tensão $(p>0,05)$. Entretanto, no material conservado em glicerina por $30(33,22 \mathrm{~mm})$, $60(34,48 \mathrm{~mm})$ e $90 \operatorname{dias}(36,99 \mathrm{~mm})$ verificou-se aumento significante $(\mathrm{p} £, 0,05)$ para os valores de alongamento, quando se compararam os dados com o do material não conservado $(26,38 \mathrm{~mm})$. Verificou-se discreto aumento da força máxima aplicada nos grupos conservados em glicerina durante $30(220,80 \mathrm{~N})$ e 90 dias $(203,92 \mathrm{~N})$, em relação aos grupos não conservado $(191,94$ N) e conservado por 60 dias $(181,65 \mathrm{~N})$, porém esta diferença não é significante $(\mathrm{p}>0,05)$.

Mediante os valores para a tensão obtidos da análise das amostras de pericárdio fibroso (Tabela 2), observou-se que tanto no material não conservado $\left(1,01 \mathrm{kgf} / \mathrm{mm}^{2}\right)$

Tabela 1 - Valores médios referentes à avaliação do centro tendíneo do diafragma bovino submetido ao ensaio mecânico de tração sem conservação (dia 0) e conservado em glicerina 98\%, nos períodos de 30, 60 e 90 dias, expressos pela média \pm desvio-padrão - Ribeirão Preto - SP - 2007

\begin{tabular}{ccccccc}
\hline Dias & Espessura $(\mathrm{mm})$ & Largura $(\mathrm{mm})$ & Área $\left(\mathbf{m m}^{2}\right)$ & Força Máxima $(\mathbf{N})$ & Tensão $\left(\mathbf{k g f} / \mathbf{m m}^{2}\right)$ & Alongamento $(\mathbf{m m})$ \\
\hline 0 & $1,65 \pm 0,38^{\mathrm{a}}$ & $18,64 \pm 0,55^{\mathrm{a}}$ & $30,77 \pm 7,44^{\mathrm{a}}$ & $191,94 \pm 45,46^{\mathrm{a}}$ & $0,66 \pm 2,24^{\mathrm{a}}$ & $26,38 \pm 4,11^{\mathrm{a}}$ \\
30 & $2,28 \pm 0,74^{\mathrm{b}}$ & $18,1 \pm 1,51^{\mathrm{a}}$ & $41,34 \pm 14,2^{\mathrm{a}}$ & $220,8 \pm 71,87^{\mathrm{a}}$ & $0,61 \pm 3,17^{\mathrm{a}}$ & $33,22 \pm 6,93^{\mathrm{b}}$ \\
60 & $1,71 \pm 0,30^{\mathrm{a}}$ & $18,9 \pm 1,13^{\mathrm{ab}}$ & $32,24 \pm 5,98^{\mathrm{a}}$ & $181_{z}, 65 \pm 52,83^{\mathrm{a}}$ & $0,57 \pm 1,73^{\mathrm{a}}$ & $34,48 \pm 7,37^{\mathrm{b}}$ \\
90 & $1,69 \pm 0,42^{\mathrm{a}}$ & $19,35 \pm 0,81^{\mathrm{b}}$ & $32,49 \pm 7,83^{\mathrm{a}}$ & $203,92 \pm 86,55^{\mathrm{a}}$ & $0,60 \pm 1,83^{\mathrm{a}}$ & $36,99 \pm 8,86^{\mathrm{b}}$ \\
\hline
\end{tabular}

Valores na mesma coluna seguidos de letras distintas diferem entre si $(\mathrm{p} \leq 0,05)$

Tabela 2 - Valores médios referentes à avaliação do pericárdio fibroso bovino submetido ao ensaio mecânico de tração sem conservação (dia 0) e conservado em glicerina 98\%, nos períodos de 30,60 e 90 dias, expressos pela média \pm desvio-padrão - Ribeirão Preto - SP -2007

\begin{tabular}{ccccccc}
\hline Dias & Espessura $(\mathrm{mm})$ & Largura $(\mathrm{mm})$ & Área $\left(\mathbf{m m}^{2}\right)$ & Força Máxima $(\mathbf{N})$ & Tensão $\left(\mathrm{kgffmm} \mathbf{m}^{2}\right)$ & Alongamento $($ mm $)$ \\
\hline 0 & $0,72 \pm 0,08^{\mathrm{a}}$ & $17,65 \pm 0,39^{\mathrm{a}}$ & $12,68 \pm 1,44^{\mathrm{a}}$ & $123,85 \pm 30,42^{\mathrm{a}}$ & $1,01 \pm 4,14^{\mathrm{a}}$ & $16,43 \pm 1,33^{\mathrm{a}}$ \\
30 & $0,52 \pm 0,10^{\mathrm{b}}$ & $17,3 \pm 1,30^{\mathrm{a}}$ & $8,99 \pm 1,90^{\mathrm{b}}$ & $124,15 \pm 33,86^{\mathrm{a}}$ & $1,43 \pm 4,80^{\mathrm{ab}}$ & $17,65 \pm 1,78^{\mathrm{a}}$ \\
60 & $0,52 \pm 0,11^{\mathrm{b}}$ & $17,82 \pm 0,94^{\mathrm{a}}$ & $9,25 \pm 1,97^{\mathrm{b}}$ & $113,83 \pm 30,42^{\mathrm{a}}$ & $1,29 \pm 4,75^{\mathrm{ab}}$ & $19,69 \pm 2,13^{\mathrm{b}}$ \\
90 & $0,4 \pm 0,08^{\mathrm{c}}$ & $17,72 \pm 1,05^{\mathrm{a}}$ & $7,07 \pm 1,39^{\mathrm{c}}$ & $113,5 \pm 34,66^{\mathrm{a}}$ & $1,65 \pm 5,76^{\mathrm{b}}$ & $20,78 \pm 2,75^{\mathrm{b}}$ \\
\hline
\end{tabular}

Valores na mesma coluna seguidos de letras distintas diferem entre si $(0 \leq 0,05)$ 
quanto naquele conservado em glicerina durante $30\left(1,43 \mathrm{kgf} / \mathrm{mm}^{2}\right)$ e 60 dias $(1,29$ $\left.\mathrm{kgf} / \mathrm{mm}^{2}\right)$, não houve alteração significante ( $>>0,05)$. Entretanto, os valores obtidos dos espécimes não conservados diferiram significantemente $(\mathrm{p} \leq 0,05)$ daqueles observados nos preservados por 90 dias $\left(1,65 \mathrm{kgf} / \mathrm{mm}^{2}\right)$. Quanto ao alongamento, os valores referentes ao material não conservado $(16,43 \mathrm{~mm})$ e ao conservado em glicerina por 30 dias $(17,65 \mathrm{~mm})$ foram significantemente $(\mathrm{p} \leq 0,05)$ inferiores ao preservado por período de $60(19,69 \mathrm{~mm})$ e 90 dias $(20,78 \mathrm{~mm})$. Verificou-se leve tendência à diminuição do valor da força máxima aplicada nos grupos conservados em glicerina durante $60(113,83 \mathrm{~N})$ e 90 dias $(113,5 \mathrm{~N})$ quando comparados aos encontrados para o material não conservado $(123,85 \mathrm{~N})$ e conservado em glicerina durante 30 dias $(124,15 \mathrm{~N})$.

No atinente à avaliação dos valores referentes às amostras testadas de peritônio parietal (Tabela 3), observou-se que não houve diferença significante $(p>0,05)$ entre a tensão do material avaliado sem conservação $\left(0,37 \mathrm{kgf} / \mathrm{mm}^{2}\right)$ e o preservado em glicerina, nos períodos de 30 (0,56 kgf/ $\left.\mathrm{mm}^{2}\right), 60\left(0,42 \mathrm{kgf} / \mathrm{mm}^{2}\right)$ e 90 dias $(0,49$ $\mathrm{kgf} / \mathrm{mm}^{2}$ ). Com relação ao alongamento, notou-se tendência de aumento nos valores relativos aos materiais conservados em glicerina, verificando-se diferença significante $(p \leq 0,05)$ entre os valores das amostras não conservadas $(18,43 \mathrm{~mm})$ e os das preservadas por período de $30(25,03 \mathrm{~mm})$ e 60 dias $(26,49 \mathrm{~mm})$. Entretanto, não se observou diferença quanto aos valores daquelas acondicionadas por 90 dias $(24,3$ $\mathrm{mm}$ ). Comparando-se a força máxima aplicada ao peritônio parietal, evidenciou-se discreto aumento nos valores para o material conservado em glicerina em relação ao fresco, porém não significante ( $\mathrm{p}>0,05)$.

No estudo comparativo das referidas membranas, constatou-se que o pericárdio fibroso, tanto não conservado quanto conservado em glicerina, suporta as maiores tensões, independentemente do período avaliado. Nas comparações realizadas entre os valores observados para o centro tendíneo do diafragma e o peritônio parietal, não houve diferença significante para os dias 30 e 90 . No entanto, o centro tendíneo do diafragma apresentou-se mais resistente quando avaliado sem conservação e conservado em glicerina por 60 dias (Tabela 4 e Figura 2). Quando confrontados os valores referentes ao alongamento verificado nos tecidos em estudo, evidenciou-se

Tabela 3 - Valores médios referentes à avaliação do peritônio parietal bovino submetido ao ensaio mecânico de tração sem conservação (dia 0) e conservado em glicerina 98\%, nos períodos de 30, 60 e 90 dias, expressos pela média \pm desvio-padrão - Ribeirão Preto - SP - 2007

\begin{tabular}{|c|c|c|c|c|c|c|}
\hline Dias & Espessura $(\mathrm{mm})$ & Largura (mm) & Área $\left(\mathrm{mm}^{2}\right)$ & Força Máxima (N) & Tensão $\left(\mathrm{kgf}^{\prime} \mathrm{mm}^{2}\right)$ & Alongamento $(\mathrm{mm})$ \\
\hline 0 & $0,61 \pm 0,16^{\mathrm{a}}$ & $17,71 \pm 0,91^{\mathrm{a}}$ & $10,74 \pm 2,9^{a}$ & $38,17 \pm 12,07^{a}$ & $0,37 \pm 1,24^{\mathrm{a}}$ & $18,43 \pm 3,66^{a}$ \\
\hline 30 & $0,49 \pm 0,24^{2 b}$ & $19,27 \pm 1,19^{\circ}$ & $9,53 \pm 5,04^{2}$ & $44,94 \pm 13,30^{a}$ & $0,56 \pm 3,10^{2}$ & $25,03 \pm 4,90^{\circ}$ \\
\hline 60 & $0,53 \pm 0,13^{a b}$ & $19,73 \pm 1,39^{b}$ & $10,5 \pm 3,17^{a}$ & $41,95 \pm 6,35^{\mathrm{a}}$ & $0,42 \pm 1,06^{\mathrm{a}}$ & $26,49 \pm 6,26^{\circ}$ \\
\hline 90 & $0,46 \pm 0,07^{\circ}$ & $20,22 \pm 1,08^{\circ}$ & $9,27 \pm 1,25^{\mathrm{a}}$ & $44,68 \pm 12,17^{a}$ & $0,49 \pm 1,54^{2}$ & $24,3 \pm 8,86^{2 b}$ \\
\hline
\end{tabular}

Tabela 4 - Valores médios referentes à tensão sofrida pelo centro tendíneo do diafragma, pericárdio fibroso e peritônio parietal bovinos submetidos ao ensaio mecânico de tração sem conservação (dia 0) e conservados em glicerina 98\%, durante 30,60 e 90 dias, média \pm desvio-padrão e coeficiente de variação (CV) Ribeirão Preto - SP - 2007

\begin{tabular}{|c|c|c|c|c|c|c|}
\hline \multirow[t]{2}{*}{ Dias } & \multicolumn{6}{|c|}{ Tensão $\left(\mathrm{kgf} / \mathrm{mm}^{2}\right)$} \\
\hline & Centro Tendineo & $C V(\%)$ & Pericárdio & $\mathrm{CV}(\%)$ & Peritônio & $\mathrm{CV}(\%)$ \\
\hline 0 & $0,66 \pm 2,24^{\mathrm{a}}$ & 0,34 & $1,01 \pm 4,14^{b}$ & 0,41 & $0,37 \pm 1,24^{c}$ & 0,33 \\
\hline 30 & $0,61 \pm 3,17^{\mathrm{a}}$ & 0,52 & $1,43 \pm 4,80^{b}$ & 0,34 & $0,56 \pm 3,10^{\mathrm{a}}$ & 0,55 \\
\hline 60 & $0,57 \pm 1,73^{\mathrm{a}}$ & 0,30 & $1,29 \pm 4,75^{b}$ & 0,37 & $0,42 \pm 1,06^{c}$ & 0,25 \\
\hline 90 & $0,60 \pm 1,83^{\mathrm{a}}$ & 0,30 & $1,65 \pm 5,76^{b}$ & 0,35 & $0,49 \pm 1,54^{\mathrm{a}}$ & 0,31 \\
\hline
\end{tabular}

Valores na mesma linha seguidos de letras distintas diferem entre si $(p \leq 0,05)$ 
Tabela 5 - Valores médios referentes ao alongamento apresentado pelo centro tendíneo do diafragma, pericárdio fibroso e peritônio parietal bovinos submetidos ao ensaio mecânico de tração sem conservação (dia 0) e conservados em glicerina 98\%, durante 30,60 e 90 dias, média \pm desvio-padrão e coeficiente de variação $(C V)$ - Ribeirão Preto - SP - 2007

\begin{tabular}{cccccccc}
\hline Dias & \multicolumn{7}{c}{ Alongamento (mm) } \\
\hline & Centro Tendineo & $C V(\%)$ & Pericárdio & $C V(\%)$ & Peritônio & $C V(\%)$ \\
0 & $26,38 \pm 4,11^{\mathrm{a}}$ & 0,16 & $16,43 \pm 1,33^{\mathrm{b}}$ & 0,08 & $18,43 \pm 3,66^{\mathrm{b}}$ & 0,20 \\
30 & $33,22 \pm 6,93^{\mathrm{a}}$ & 0,21 & $17,65 \pm 1,78^{\mathrm{b}}$ & 0,10 & $25,03 \pm 4,90^{\mathrm{c}}$ & 0,20 & 0,24 \\
60 & $34,48 \pm 7,37^{\mathrm{a}}$ & 0,21 & $19,69 \pm 2,13^{\mathrm{b}}$ & 0,11 & $26,49 \pm 6,26^{\mathrm{c}}$ & & 0,36 \\
90 & $36,99 \pm 8,86^{\mathrm{a}}$ & 0,24 & $20,78 \pm 2,75^{\mathrm{b}}$ & 0,13 & $24,3 \pm 8,86^{\mathrm{b}}$ & & 0,36 \\
\hline
\end{tabular}

Valores na mesma linha seguidos de letras distintas diferem entre si $(p \leq 0,05)$

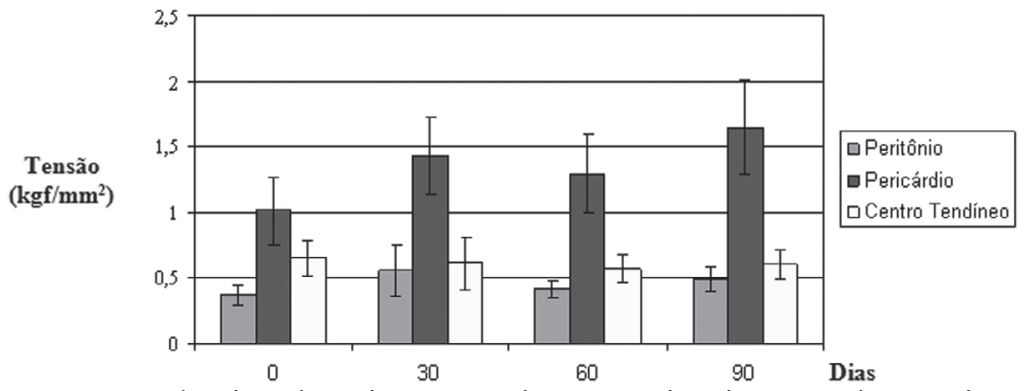

Figura 2 - Representação gráfica dos valores da tensão média e erro-padrão dos corpos de prova de centro tendíneo do diafragma, pericárdio fibroso e peritônio parietal bovinos submetidos ao ensaio mecânico de tração sem conservação (dia 0) e conservados em glicerina a 98\%, durante 30, 60 e 90 dias

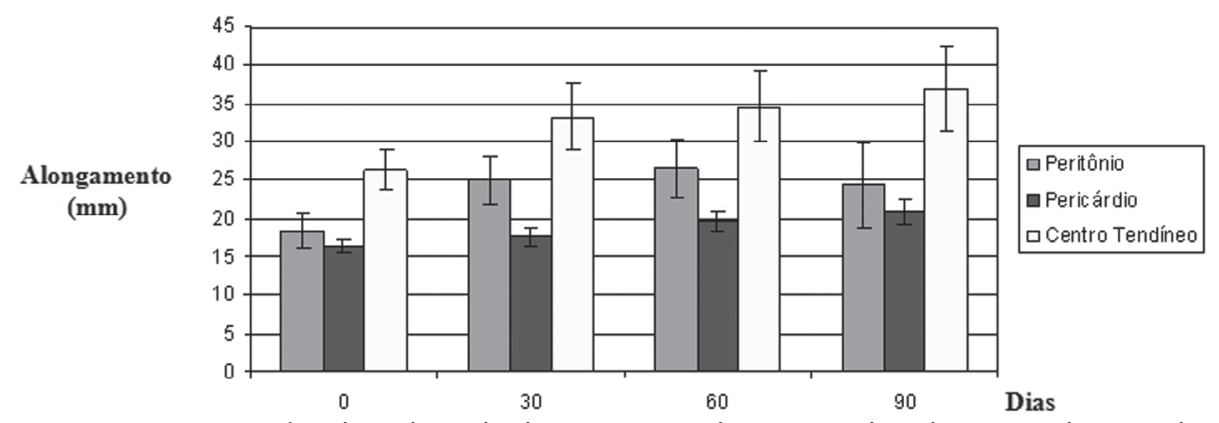

Figura 3 - Representação gráfica dos valores de alongamento médio e erro-padrão dos corpos de prova de centro tendíneo do diafragma, pericárdio fibroso e peritônio parietal bovinos submetidos ao ensaio mecânico de tração sem conservação (dia 0) e conservados em glicerina a 98\%, durante 30,60 e 90 dias

que o centro tendíneo do diafragma, diferentemente das observações atinentes à tensão, apresentava-se como o material mais elástico, independentemente do período avaliado, seguido pelo peritônio parietal e pericárdio fibroso (Tabela 5 e Figura 3).

\section{Discussão}

Avaliando as membranas em questão, constatou-se que estas se enquadram na classe de materiais com propriedade viscoelástica não-linear, conforme descreveu Dal Fabro citado por Wu et al. ${ }^{5}$.
No que se refere aos corpos de prova, estes, ao serem submetidos à imposição de uma força axial externa de tração, da qual se origina um fenômeno denominado "fenômeno de constrição", ou seja, tanto a área de secção do segmento quanto a parede da região central dos espécimes sofrem estreitamento e, conseqüentemente, alteração no valor da área em cada instante de aplicação da força (WU apud WU et al. ${ }^{5}$ ). Tais observações também foram constatadas nos corpos de prova do presente estudo, exceto em alguns exemplares de centro tendíneo do diafragma, que 
tiveram seu ponto de ruptura deslocado para a extremidade da amostra, dada a fragilidade que a parte mediastinal da pleura parietal conferiu à região.

Desse modo, as colocações de Wu et al. ${ }^{5}$ de que a constante de elasticidade dos corpos de prova modifica-se com a ação da força axial, em decorrência das microrrupturas que ocorrem a cada momento da tração, com conseqüente alteração da disposição celular e fibrilar do tecido, foram comprovadas nesta oportunidade, à semelhança dos autores citados, mediante a avaliação histológica das amostras após a realização dos testes mecânicos, evidenciando-se a presença de espaçamentos difusos, os quais promovem o afastamento das fibras colágenas, ocasionando perda de resistência e conseqüente ruptura.

Os valores registrados na literatura consultada referentes à área de secção dos corpos de prova não coincidem com os encontrados no presente estudo. Tal fato deve-se provavelmente à metodologia diferente utilizada neste experimento, no tocante às dimensões dos corpos de prova e parâmetros de ensaio (velocidade de aplicação de carga). Assim, embora se tenha observado nesta pesquisa diferença marcante no valor da largura das amostras, o valor da espessura dessas estruturas era bem próximo aos valores da espessura do peritônio bovino ${ }^{7}$ e do pericárdio bovino. ${ }^{8}$

Constatou-se no presente estudo que o centro tendíneo do diafragma suporta a maior carga para força máxima de tração $(220,8 \pm 71,87 \mathrm{~N})$, seguido pelo pericárdio fibroso $(124,15 \pm 33,86 \mathrm{~N})$ e pelo peritônio parietal $(44,94 \pm 13,30 \mathrm{~N})$, todos conservados por 30 dias em glicerina. Estas observações estão de acordo com as informações de Abrahão et $a .^{7}$ para o peritônio bovino não conservado $(51,53 \pm 4,05 \mathrm{~N})$ e para o conservado em glicerina por 30 dias $(58,61 \pm 5,01 \mathrm{~N})$.

Quanto aos valores ora encontrados para a força máxima de tração, estes diferem dos descritos por Rabelo et al. ${ }^{9}$, que observaram para o centro tendíneo bovino não conservado valor de 4,61 $\pm 0,97 \mathrm{~N}$, conservado em glicerina por 30 dias, $4,28 \pm 0,79 \mathrm{~N}$, e para o conservado em glutaraldeído por 30 dias valor de $5,58 \pm 1,25 \mathrm{~N}$. Diferem também das observações de Costa et al. ${ }^{10}$, que registraram para o pericárdio bovino não conservado valor de $28,0 \pm 6,0 \mathrm{~N}$ e para o descelularizado valor de $10,0 \pm 6,0$ $\mathrm{N}$. Estes podem ser atribuídos à menor área de secção do material analisado por estes autores, quando comparados à área de secção das amostras estudadas neste trabalho.

De acordo com Pigossi ${ }^{2}$ e Noorth et al. apud Wells, Yeh e Humphrey ${ }^{11}$, ao analisarem a dura-máter canina e humana, respectivamente, após conservação em glicerina, observaram aumento na resistência dessas membranas quando tracionadas. Estas informações são discordantes das encontradas neste estudo, onde os maiores valores para a força máxima foram observados aos 30 dias de preservação além de tendência à manutenção desta quando aplicada nos materiais conservados por até 90 dias. Entretanto, evidenciou-se diminuição da força máxima aplicada ao peritônio parietal aos 60 e 90 dias de conservação. Porém, estes valores não apresentaram diferenças significantes.

Quanto à tensão que é suportada pelas membranas biológicas, para o pericárdio bovino não conservado são descritos valores em torno de 0,84 $\pm 0,21$ $\mathrm{kgf} / \mathrm{mm}^{2}$ (FORTI; GOISSIS; PLEPIS, $2006^{8}$ ) e de $3,0 \pm 0,6 \mathrm{kgf} / \mathrm{mm}^{2}($ COSTA et al. $\left.{ }^{10}\right)$, para o pericárdio bovino descelularizado, valor de 1,0 $\pm 0,3 \mathrm{kgf} /$ $\mathrm{mm}^{2}$ (COSTA et al. ${ }^{10}$ ) e para o pericárdio bovino tratado em glutaraldeído $0,05 \%$ por 2 horas, valor de $1,06 \pm 0,34 \mathrm{kgf} /$ $\mathrm{mm}^{2}$ (FORTI; GOISSIS; PLEPIS, 2006 ${ }^{8}$ ). Estes valores aproximam-se dos encontrados neste estudo para o pericárdio fibroso bovino, tanto sem conservação $\left(1,01 \mathrm{kgf} / \mathrm{mm}^{2}\right)$, quanto 
conservado em glicerina por 30 dias $(1,43$ $\left.\mathrm{kgf} / \mathrm{mm}^{2}\right), 60$ dias $\left(1,29 \mathrm{kgf} / \mathrm{mm}^{2}\right)$ e 90 dias $\left(1,65 \mathrm{kgf} / \mathrm{mm}^{2}\right)$.

O valor da tensão descrito para o pericárdio bovino não conservado ${ }^{10}$ difere das demais observações, sugerindo que a seleção das amostras para a realização dos ensaios mecânicos interferiu nos valores encontrados, uma vez que os autores utilizaram apenas amostras padronizadas para a confecção de biopróteses valvares.

Embora se tenha observado maiores valores para as forças de tração aplicadas aos corpos de prova de centro tendíneo do diafragma bovino avaliados neste estudo, constatou-se para sua tensão valores entre 0,57 e $0,66 \mathrm{kgf} / \mathrm{mm}^{2}$. Estes são inferiores aos encontrados para o pericárdio fibroso $\left(1,01 \mathrm{a} 1,65 \mathrm{kgf} / \mathrm{mm}^{2}\right)$, porém maiores do que os apresentados pelo peritônio parietal, que dentre os tecidos avaliados foi o que exibiu menores valores para a tensão $(0,37$ a $0,56 \mathrm{kgf} /$ $\left.\mathrm{mm}^{2}\right)$. Esta diferença pode ser explicada pela maior área de secção apresentada pelos corpos de prova de centro tendíneo do diafragma em relação aos demais (Tabelas 1 a 3).

Verificou-se para todas as membranas estudadas, que o aumento no tempo de conservação em glicerina promovia diminuição em sua rigidez. Tal situação foi evidenciada pela diferença nos valores de alongamento apresentados tanto pelas amostras analisadas sem conservação, quanto naquelas conservadas em glicerina por até 90 dias. Estas informações se assemelham às observações de Abrahão et al. ${ }^{7}$ ao relatarem diferenças significativas para o alongamento do peritônio bovino não conservado $(16,58 \pm 0,58 \mathrm{~mm})$ e conservado em glicerina por 60 dias $(28,93 \pm 1,54 \mathrm{~mm})$, coincidindo com o alongamento observado para o peritônio parietal avaliado neste estudo, que exibiu os maiores valores de alongamento aos 60 dias de conservação em glicerina.

De acordo com Costa et al. ${ }^{10}$, o pericárdio bovino não conservado, quando submetido à tração, distende-se por cerca de $20,0 \%$ de seu comprimento inicial, valor que se aproxima do descrito para este mesmo tecido sem conservação $(23,5 \%)$ e tratado em glutaraldeído $0,05 \%$ por 2 horas $(27,2 \%)$, segundo os relatos de Forti, Goissis e Plepis 8 . Também estão próximos aos valores observados neste estudo, no qual o pericárdio fibroso não conservado apresentou alongamento em torno de $32,86 \%$ de seu comprimento inicial, além daqueles preservados em glicerina durante 30 dias (35,3\%), 60 dias (39,38\%) e 90 dias (41,56\%). Estes achados são atribuídos à ação da glicerina no tecido, tal qual descreveu Reyes ${ }^{12}$ para o pericárdio e para a fáscia lata de eqüinos conservados em glicerina, por 30 ou 40 dias. Entretanto, Pigossi $^{2}$ não constatou alteração no grau de elasticidade da dura-máter canina conservada em glicerina, da mesma forma que Noorth et al. apud Wells, Yeh e Humphrey ${ }^{11}$, quando analisaram a dura-máter humana após imersão em glicerina e subseqüente reidratação.

\section{Conclusões}

Ao analisar os valores da força máxima de tração, notou-se que o centro tendíneo do diafragma suportou as maiores cargas. Entretanto, quando calculadas as tensões dos corpos de prova, que relacionam a força máxima de tração com a área de secção dos mesmos, evidenciou-se que o pericárdio fibroso se apresentou como o tecido mais resistente quando comparado com o centro tendíneo do diafragma e com o peritônio parietal.

Quanto à ação da glicerina, pode-se observar diminuição na rigidez dos tecidos testados evidenciada pelo aumento na elasticidade dos materiais nela preservados por até 90 dias, não havendo interferência significante na resistência das membranas estudadas.

\section{Agradecimentos}

Ao Laboratório de Bioengenharia da Faculdade de Medicina da Universidade de São Paulo, Ribeirão Preto - SP. 


\section{Compared tensiometrical properties between non conserved and glycerin conserved fragments of bovine diaphragma's tendinous center, fibrous pericardium and parietal peritoneum}

\section{Abstract}

The behaviour of the non conserved and $98 \%$ glycerin conserved specimens for periods of 30,60 and 90 days of bovine diaphragma's tendinous center, fibrous pericardium and parietal peritoneum submitted to mechanical tests of traction, was observed in ten bovines between 30 months and 36 months of age, crossbreeds, males and females, collecting fragments of these aforesaid membranes in each animal. The diaphragma's tendinous center and parietal peritoneum did not suffered significant modification $(p>0.05)$ in the values of tension when compared to the resistance tests of traction of non conserved and $98 \%$ glycerin conserved membranes. However, all the evaluated tissues showed significant increase $(\mathrm{p}, 0.05)$ of the elongation values when conserved in 98\% glycerin for until 90 days. It was also observed that fibrous pericardium is the one which supports greaters tensions. So, it to was concluded, that glycerin is efficient to the conservation of biological membranes besides modifying its mechanical properties.
Key words: Bovines.

Tendinous center Pericardium. Peritoneum. Mechanical tests.

\section{Referências}

1 BATISTA, L. C.; DALECK, C. R.; SHIMANO, A. C.; ALESSI, A. C.; ABRAHÃO, M. S. Estudo comparativo da resistência à tração do peritônio (bovino, eqüino, suíno e canino) a fresco e conservado em glicerina. Brazilian Journal of Veterinary Research and Animal Science, v. 33, p. 305-312, 1996. Supplement.

2 PIGOSSI, N. Implantação de dura-máter homógena conservada em glicerina - estudo experimental em cães. 1964. 41 f. Tese (Doutorado) - Faculdade de Medicina, Universidade de São Paulo, São Paulo, 1964.

3 ALVARENGA, J. Possibilidades e limitações da utilização de membranas biológicas preservadas em cirurgia. In: DALECK, C. R.; BAPTISTA, L. C.; MUKAI, L. S. Tópicos em cirurgia de cães e gatos. Jaboticabal: FUNEP-UNESP, 1992. p. 33-42.

4 BASTOS, E. L. S.; FAGUNDES, D. J.; TAHA, M. O.; NOVO, N. F.; SILVADO, R. A. B. Peritônio bovino conservado na correção de hérnia ventral em ratos: uma alternativa para tela cirúrgica biológica. Revista do Colégio Brasileiro de Cirurgia, v. 32, n. 5, p. 256-260, 2005.

5 WU, F. C.; LEE, H. D.; MACHADO, R. B.; DALMÁS, S.; COY, C. S. R.; GÓES, J. R. N.; FAGUNDES, J. J. Apresentação do teste energia total de ruptura para avaliação de material biológico com propriedade viscoelástico não-linear. Acta Cirúrgica Brasileira, v. 19, n. 6, p. 609-616, 2004

6 TRIOLA, M. F. Introdução à estatística. 9. ed. Rio de Janeiro: LTC, 2005. 682 p.

7 ABRAHÃO, M. S.; SHIMANO, A. C.; PAULIN, J. B. P.; DALECK, C. R. Estudo comparativo da resistência à tração do peritônio de bovino a fresco e conservado em glicerina. In: FÓRUM NACIONAL DE CIÊNCIA E TECNOLOGIA EM SAÚDE, 1., 1992, Caxambu. Resumo ... Caxambu: SBEB, 1992. p. 22-25.

8 FORTI, F. L.; GOISSIS, G.; PLEPIS, A. M. G. Modifications on collagen structures promoted by 1,4 dioxane improve thermal and biological properties of bovine pericardium as a biomaterial. Journal of Biomaterials Applications, v. 20, n. 3, p. 267-285, 2006.

9 RABELO, R. E.; TAVARES, G. A.; PAULO, N. M.; SILVA, L. A. F.; DAMASCENO, A. D.; ANDRADE, M. A.; MARTINS, F. G.; ROMANI, A. F.; SILVA, O. C.; TRINDADE, B. R. Características físicas e microbiológicas do centro tendíneo diafragmático bovino conservado em glicerina a $98 \%$ e no glutaraldeído a $4 \%$. Ciência Animal Brasileira, v. 5, n. 4, p. 229-238, 2004.

10 COSTA, J. N. L.; POMERANTZEFF, P. M. A.; BRAILE, D. M.; RAMIREZ, V. A.; GOISSIS, G.; STOLF, N. A. G. Comparação entre o pericárdio bovino descelularizado e o pericárdio bovino convencional utilizado na confecção de biopróteses valvares cardíacas. Revista Brasileira de Cirurgia Cardiovascular, v. 20, n. 1, p. 1422, 2005.

11 WELLS, P. B.; YEH, A. T.; HUMPHREY, J. D. Influence of glycerol on the mechanical reversibility and thermal damage susceptibility of collagenous tissues. IEEE Transactions on Biomedical Engineering, v. 53, n. 4, p. 747-753, 2006

12 REYES, E. E. F. Testes físicos comparativos de membranas biológicas preservadas em glicerina, congeladas e a fresco. 1993. 85 f. Dissertação (Mestrado em Cirurgia Veterinária) - Faculdade de Medicina Veterinária e Zootecnia, Universidade de São Paulo, São Paulo, 1993. 